\title{
Modes of variability in the climate system: Past-Present-
}

\section{Future}

European Science Foundation Conference - Ötztal, Austria, 27 May - 1 June 2012

\author{
Hubertus Fischer ${ }^{1}$ and ERIC W. WolfF ${ }^{2}$ \\ 'Climate and Environmental Physics and Oeschger Centre for Climate Change Research, University of Bern, Switzerland; hubertus.fischer@ \\ climate.unibe.ch \\ 2British Antarctic Survey, Cambridge, UK
}

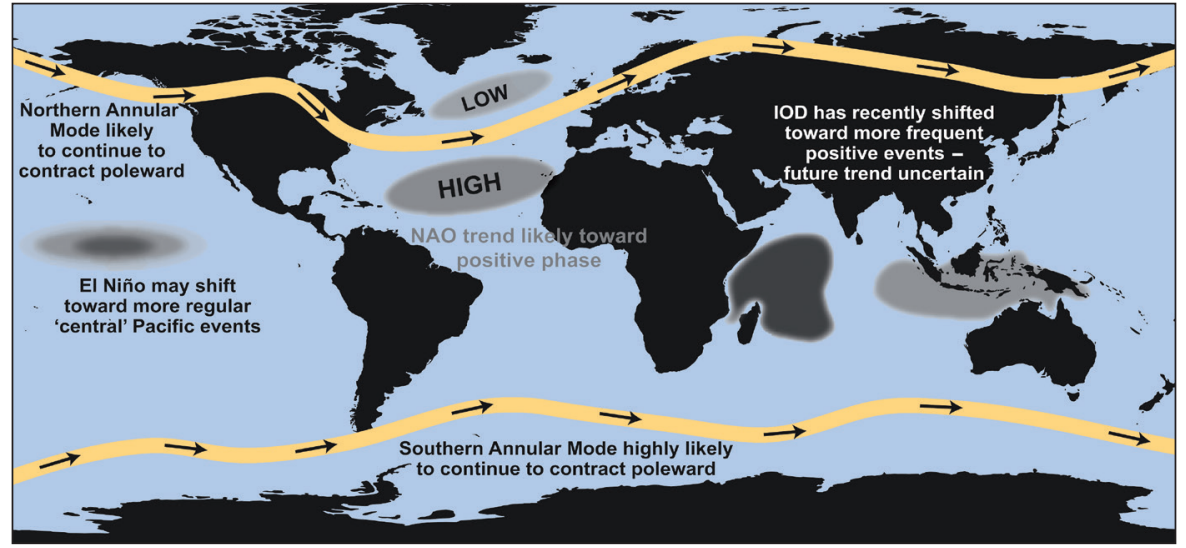

Figure 1: Schematic diagram showing the major modes of climate variability and how they are likely to change in the future. The high-latitude modes have already undergone significant change over the past century. Trends in the tropical modes (ENSO, Indian Ocean Dipole IOD) have been detected in the more recent climatological record (from England 2011).

A ssessing the ongoing climate warming demands a detailed understanding of global and regional climate variations as well as the capacity to forecast future changes using climate models. While greenhouse gas forcing affects climate globally, it is the regional changes that have a direct impact on individual welfare and societies. Moreover, spatially representative climate modes and teleconnection patterns offer the means to contrast rather coarsely-resolved climate models to point-wise paleoclimate data.

Accordingly, modes of climate variability and their biogeochemical impact were the subject of this conference. The first session provided the background on the definition of modes and teleconnection patterns based on observational evidence. Moreover, the physical context of atmospheric and oceanic teleconnections by advection and wave propagation was provided.

Session 2 focussed on tropical climate variability. Latest results show that the ENSO impact is not confined to the tropical Pacific but that hydrological changes and wave propagation transfer energy to other ocean basins. However, representation of ENSO in global climate models is still not satisfactory, hampering progress in making predictions. Past monsoon intensity was another discussion point. It appears to be highly controlled by the Atlantic Meridional Overturning Circulation (AMOC) and concurrent changes in the Intertropical Convergence Zone.
Completely different boundary conditions for modes of climate variability prevailed during the last glacial, which was the topic of session 3. Model studies show that the topography of ice sheets has a strong control on the teleconnection patterns in the North Atlantic and also likely in the Southern Ocean. Moreover the phase relationship between ice sheet retreat, greenhouse gases and ocean circulation shows that climate changes in the Southern Ocean slightly preceded the $\mathrm{CO}_{2}$ increase over the transition, while increasing $\mathrm{CO}_{2}$ accelerated ice sheet loss in the northern hemisphere and led climate changes in the North.

Extratropical teleconnection patterns were the subject of session 4. Reconstructions show that the North Atlantic Oscillation (NAO) also has far-field connections to adjacent regions. The discussion showed that field reconstructions are more desirable for NAO analysis compared to two-point indices. For the Southern Ocean region the Southern Annular Mode (SAM) is the most important teleconnection pattern. Latest results show that both ozone and greenhouse gases can change the location of the southern jet stream and the Southern Ocean westerlies. The lack of a sufficient representation of the stratosphere/troposphere coupling in many models is a major caveat for the model response of the SAM to climate changes.

Session 5 raised the discussion that changes in the ocean circulation modes such as the AMOC and the Antarctic Circumpolar Current can also cause strong changes in inter-hemispheric heat transport and atmospheric $\mathrm{CO}_{2}$ levels. During the glacial, proxy evidence shows that a less-ventilated, carbon enriched water mass prevailed in the Southern Ocean extending into the deep North Atlantic as well as into intermediate waters. Changes in both the southern westerly winds and in the AMOC are able to disrupt this water mass, bringing old $\mathrm{CO}_{2}$ back to the surface. Model studies also show that changes in the AMOC lead to rapid hemispheric responses in climate and the hydrological cycle, which are essentially synchronous with the shut-off of the AMOC.

Changes in the AMOC also have strong impacts on tropical and boreal wetlands and, thus, methane emissions as discussed in session 6. Another influence of changing modes on biogeochemical cycles is the control of the southern westerly wind belt on dust mobilization and transport in the Southern Ocean region, which also strongly affects marine bioproductivity. Ecological studies show that export production can be significantly enhanced by iron fertilization. However, this is not always the case - it depends on complex ecological interaction within the trophic chain and the competition between calcareous and silicious plankton groups.

In addition to invited lectures and poster sessions, several interactive discussions were organized to identify the major gaps and stumbling blocks in research on modes and teleconnection patterns and potential solutions. The conference demonstrated unequivocally that trans- and interdisciplinary research is required to move forward in this field of strong societal importance.

\section{Acknowledgements}

This Conference was co-sponsored by PAGES, the EPICA Descartes Prize, the Oeschger Centre for Climate Change Research (University of Bern, Switzerland), and the German Research Foundation through the project INTERDYNAMIK (University of Bremen, Germany).

\section{Reference}

England MH (2011) In: Richardson K, Steffen W, Liverman D (Eds) Climate Change: Global Risks, Challenges and Decisions, Cambridge University Press, 33-35 